\title{
Analysis on the Sustainable Development Value of Urban Eco-sports
}

\author{
Fan Zhang \\ Department of Police Skills and Tactics, Nanjing Forest Police College, Nanjing 210023, China \\ Sports Science postdoctoral programme, Nanjing Normal University, Nanjing 210023, China \\ zhangfan@nfpc.edu.cn
}

Keywords: City, Eco-sports, Sustainable Development, Value research.

\begin{abstract}
Urban eco-sports emphasizes the ecological awareness and ecological thinking of individuals, and pursues the coordinated development and harmonious coexistence of sports and environment; eco-sports points out the correct direction for the development of current social sports; especially, its sustainable development value has a very important positive role in promoting the development of urban economy and culture, promoting citizens' sports awareness, and developing national fitness. Therefore, it is particularly important to study the sustainable development value of urban eco-sports. Based on the definition and characteristics of urban eco-sports, this paper makes an in-depth analysis on the constraints against sustainable development value of urban eco-sports by means of literature, expert interviews and questionnaires, and puts forward corresponding countermeasures to achieve the harmonious development of man and nature, society and oneself.
\end{abstract}

\section{Introduction}

The intensifying global environmental crisis since the end of the 20th century has caused extreme panic and high attention. In order to resolve various negative factors faced by modern sports and help them out of predicament, ecology began to enter people's vision, followed by eco-sports. Eco-sports has gradually become an important choice for the development of sports industry, it is an important component of the construction of ecological civilization. It does not have a clear boundary but can be integrated into all aspects of social, economic, political and cultural construction in China. It advocates saving resources and protecting environment [1]; the basic idea is people-oriented, and ultimate goal is to achieve harmonious coexistence among human and oneself and promote sustainable development of society, environment and resources. Developing and researching the sustainable development value of urban eco-sports are the inevitable requirement of building an eco-civilized city. It is helpful to cultivate people's awareness of environmental protection, enhance the sense of responsibility and mission of social groups for environmental protection, and form a good atmosphere for protecting the environment in the whole society. In addition, it is a powerful guarantee to promote the development of urban sports industry, helps to improve the way of sports activities of urban residents, provides more convenient conditions for participation in sports activities, helps them form a civilized, healthy and harmonious lifestyle, and in turn, promotes them to actively participate in sports activities; it tries every means to make use of the limited natural ecological environment, artificial environment and provincial capital ecological environment to carry out sports activities so as to achieve the coordinated development of sports, culture and ecological environment.

\section{Overview of Urban Eco-sports}

\subsection{Definition of Urban Eco-sports}

Urban eco-sports, a new concept derived from social development and a sport carried out in the natural and social ecological environment, pursues the harmonious development between urban sports and urban ecological environment [2]. They promote and penetrate each other, which is 
manifested in the coordinated development and harmonious coexistence between man, nature and society, among which ecology is the core part of urban eco-sports. When participating in sports activities, on the basis of respecting the basic sports ethics and morals, people should have a strong ecological awareness, firm the harmonious, progressive, peaceful and natural concept of green sports, and actively participate in the protection of ecological environment.

\subsection{Characteristics of Urban Eco-sports}

\subsubsection{Urban Eco-sports Are Cultural}

Urban eco-sports are cultural, which is reflected in its pursuit of spiritual culture. Over a long time, spiritual culture has been a kind of inheritance of Chinese nation's excellent culture, it involves all aspects of social life e.g. ethics, social customs, laws and regulations, religious beliefs. It is a system of values shared and recognized by the whole society. Under the current social environment, eastern sports and western sports have relatively mature exchanges and communication, which are the obvious reflection of cultural characteristics of urban eco-sports.

\subsubsection{Urban Eco-sports Are Natural}

From the sole perspective of evolution of sports activities, it is the ecological adjustment for human society. It can first adjust people's psychological and physiological state to realize the adjustment of value of life, and fundamentally improve people's living and life quality. Sports shapes and improves people's behavior through a certain way of behavior, helps to strengthen their knowledge of natural and social attributes, promotes people to develop in a positive direction, and helps the whole society to develop a good habit of participating in physical exercise [3]. In terms of the development speed of current outdoor sports, sports has become an important part of people's lives.

\subsubsection{Urban Eco-sports Are Social}

The development of eco-sports is inseparable from certain social environment and closely related to social sports. Nowadays, with the rapid development of society, people's health index constantly decreases. Irregular work, unhealthy eating habits, overloaded psychological stress and other factors invisibly damage people's health and life. At this time, social sports need to be combined with the actual situation of social development to constantly meet people's new needs for sports activities.

\section{Problems of Sustainable Development Value of Urban Eco-sports in Development}

\subsection{Social groups Lack Knowledge of Eco-sports, and Urban Planning Is Unreasonable}

As the public service supply subject, administrative departments and various sports organizations play a very important role in the development of urban eco-sports, e.g. the Ministry of Environmental Protection, the Ministry of Sports, the Ministry of Urban Planning. In addition, sports teachers, coaches, referees, sports enthusiasts and other social groups lack correct understanding of eco-sports, with relatively weak awareness; their understanding of eco-sports is still in the sports activities developed in natural environment, and holding that there is no or few eco-sports in the city. At the same time, there is also a lack of systematic and complete eco-sports planning pattern in sports governance with individual participation. More attention is focused on the hardware provision of sports facilities but ignoring the consideration of soft environment, resulting in that social groups can not actively participate in certain sports activities.

\subsection{Competitive Sports Occupy Too Much Resources, and the Development of Sports Industry Is Unbalanced}

In recent years, with the development of society, the development of China's sports industry can not keep up with the pace, the development of overall structure is unbalanced. It is manifested in the unbalanced structure among sports departments and the unbalanced development of main sports 
industries such as mass sports and competitive sports. Under the guidance of Olympic Glory Program, competitive sports occupy too much administrative and financial resources, and squeeze the investment in mass sports to a large extent, leading to its lagged development [4,5]. However, with the improvement of material life and enhancement of physical fitness awareness, mass sports need to be expanded, but the supply is seriously backward. Although China's sports industry has gained some support from policy and market in recent years, the development of sports industry is still slow and in infancy, which is closely related to its unreasonable development structure. Sports goods manufacturing industry occupies most of output value, sports competition \& performance industry and sports fitness entertainment industry have "much cry and little wool", with seriously insufficient hematopoietic capacity.

\subsection{Frequent Environmental Problems Lead to the Reduction of Eco-sports Effectiveness}

The development of urban eco-sports can not be separated from a certain environment; once there is a problem in environment, the effectiveness of eco-sports is out of the question. In recent years, people blindly pursue economic growth; the environmental damage is relatively serious, such as greenhouse effect, soil erosion, air pollution, climate pollution, etc.; with the deterioration of natural environment, water and soil resources, ice and snow resources, forest resources in China have met unprecedented challenges and become the objective factors affecting the sustainable development of urban eco-sports. The problems of natural environment and urban environment of China should not be underestimated.

\section{Optimization Countermeasures for Sustainable Development Value of Urban Eco-sports}

\subsection{Establishing and Improving Relevant Policies and Regulations, and Promoting the Integration of Ecological Environment with Sports Development Planning}

Promoting the sustainable development value of urban eco-sports is inseparable from government's firm and lasting support of policies and regulations; it should ensure that people's actions are legitimate, supported by sound and scientific concepts; the city is established with a good ecological environment; it should also develop environmental protection, always put the sustainable development of city in the first place of urban development, promote the participation of the whole citizens, and create certain social and economic benefits [6]. From the perspective of ecological environment and sports development, urban construction and development planning help to achieve impressive results and promote sustainable urban development. It can start with the venues and facilities planning of eco-sports activities, rationally layout the sports areas in urban streets and communities, make every resident participate in green aerobic outdoor sports as far as possible, maximize the basic guarantee to provide national fitness services for each resident to achieve the harmonious development among urban population distribution and urban function planning, ecological environment and develop urban eco-sports culture.

\subsection{Strengthening the Concept of Eco-sports and Cultivating the Awareness of National Fitness}

Under the background of economic and social transformation, all kinds of negative factors e.g. intensified social competition, intensified mental stress, overloaded psychological pressure, irregular life and rest, unhealthy eating habits are constantly impacting people's physical and mental health. From its epistemological roots, this health crisis is largely due to the fact that people have not yet formed a new concept of eco-sports that conforms to the development of society and the times [7]. Therefore, in order to realize the sustainable development of sports ecology, it is necessary to strengthen eco-sports concept, cultivate national fitness consciousness, create an ecological civilization society, vigorously advocate the new concept of harmony and unity of eco-sports and environment, and help them fully understand the importance of harmonious development among man and nature and society. so as to actively promote the ecological value and healthy development of urban eco-sports, encourage all social personnel to participate in the construction of sports industry, 
establish an ecological city, and optimize the relationship among man, nature and society.

\subsection{Scientifically and Appropriately Developing Eco-sports By Virtue of Natural Resources and Modern Technology}

We should speed up the pace of training and developing talents, build a high-level cultural work force and promote the prosperity and development of community leisure culture in China. First of all, we can continue to educate the original community culture workers and improve their cultural quality. Most of the existing workers are traditional workers with rich experiences in cultural undertakings but lack of understanding of the culture of new era. We should give full play to their advantages and train them to meet the needs of cultural development in new era. Secondly, we should introduce innovative talents to enhance the vitality of cultural development [8]. College students can be introduced. They are a group with strong creativity, active thinking and rich theoretical knowledge. Of course, due to the lack of practical foundation, they should be strengthened and cultivated. Finally, we should improve the welfare and treatment of community cultural workers to arouse their enthusiasm for work, and improve their social status so that they can concentrate on work for community cultural undertakings and serve community residents.

\section{Summary}

Urban eco-sports is an expression of the harmonious coexistence of human, ecological environment and sports. It contains an extremely fresh vitality, and will certainly gain more sustainable development with the support of modern society and technology. Eco-sports break through the tension between man and nature, greatly improve the eco-economic structure of urban sports, contribute to the development of sports environment-protection industry, help to achieve the optimal allocation of ecological resources; its sustainable development value will fundamentally promote the coordinated development and harmonious coexistence of environment, economy and society, and create a green environment for the harmonious and balanced development of man, nature and society.

\section{Acknowledgements}

This research was financially supported in part by the Project of China Postdoctoral Science Foundation under Grant 2017M611849, in part by the Project of the Fundamental Research Funds for the Central Universities under Grant LGZD201805, in part by the 13th Five-Year plan project of Jiangsu Education Science under Grant C-c/2018/01/11, in part by Jiangsu Qing Lan Project under Grant 2017, and in part by Pre-research project of Nanjing Forest police College under Grant LGY201603, and in part by Nanjing Forest police College Teaching Reform Project under Grant ZD18104.

\section{References}

[1] LIU Shaoying, Research on Ecological Strategy Choice and Sustainable Development of Sports Tourism Industry in Western Region of China, China sport science and technology. 41 (2005) 3-5.

[2] TAO Ping, Development of Circular Economy of Rural Sports Tourism: Based on the Perspective of Low Carbon Ecological, Journal of Shenyang Sport University. 33(2014) 64-67.

[3] Yang Peifeng and Cai Yunnan, The Research on Urban Space Development Based on the Natural Ecological Vision: Case of Chengdu City, Chinese landscape architecture. 20 (2004) 48-55.

[4] JIA Xue-jun, A Systematic Study and the Evaluation of Deep Ecology, Journal of gansu lianhe university (social science edition). 23 (2007) 5-9.

[5] Wang Guangan, Analysis on Domestic Marathon Hot Based on Sociological Perspective, Bulletin of Sport Science \& Technology. 25 (2017) 114-145. 
[6] Chen Hao, Ren Yuyong, Wang Li, et al., Sustainable Development of Ecological Sports Tourism: A Case Study of the Beijing-Hangzhou Grand Canal, Journal of Beijing Sports University. 38 (2015) 26-32.

[7] NA Na, Reflections on the Deep Ecology of Urban Planning Based on Deep, Journal of yunnan rtv university. 11 (2009)80-83.

[8] Zhou Cheng, Jinchuan, Zhao Biao, et al., The provincial difference of coupling coordinative development of regional economy-ecology-tourism, Journal of Arid Land Resources and Environment. 30 (2009) 203-208. 